\title{
Pengenalan Kebudayaan Indonesia melalui Fotografi pada Akun Instagram "KWODOKIJO"
}

\author{
Maya Purnama Sari ${ }^{1}$, Ali Rahmat Hidayatulloh ${ }^{2}$ \\ 1,2) Prodi Pendidikan Mutlimedia Kampus Cibiru, Universitas Pendidikan Indonesia Jl. Raya Cibiru Km \\ 15 Bandung 40393 \\ Email: mayapurnama@upi.edu, ali.rahmat@upi.edu
}

\begin{abstract}
ABSTRAK
Kebudayaan merupakan identitas bangsa Indonesia, kekhasan serta keragamannya perlu ditanamkan, dicintai oleh warga Indonesia serta dapat diperkenalkan kepada seluruh dunia. Kemudahan teknologi saat ini mampu menjangkau genarasi muda yang ingin mengenal kebudayaan Indonesia dengan segala kemudahannya, salah satu teknologi hasil karya fotografi dapat menjadi fasilitas dalam mengenal kebudayaan Indonesia. Tujuan dari penelitian yaitu mengenal kebudayaan Indonesia dari unsur kebudayaan secara universal dari hasil karya fotografi akun Instagram "kwodokijo". Metode penelitian menggunakan pendektaan kualitatif deskriptif dengan studi literatur hasil karya fotografi serta kebudayaan Indonesia. Hasil penelitian ini menunjukan bahwa dari ketujuh unusr kebudayaan secara iniversal, hasil karya kwodokijo hanya menunjukan enam unsur kebudayaan, yang tercipta secara lisan tidak terekam oleh fotografi. Sistem Bahasa. Seluruh hasil karya "kwodokijo" Sangat mencerminkan situasi dan kondisi kebudayaan asli Indonesia yang dapat menjadi identitas bangsa, dengan mudah dapat diakses oleh masyarakat local dan dunia dari berbagai kalangan.
\end{abstract}

Kata kunci: Fotografi, Kebudayaan Indonesia, Unsur Kebudayaan

\begin{abstract}
Culture is the identity of the Indonesian nation, its uniqueness and diversity need to be instilled, loved by Indonesians and can be introduced to the whole world. The ease of technology is currently able to reach the young generation who want to know Indonesian culture with all its conveniences, one of the technologies made by photography can be a facility in getting to know Indonesian culture. The purpose of this research is to know Indonesian culture from universal cultural elements from the photographic work of the Instagram account "kwodokijo". The research method used a descriptive qualitative approach with literature study of photography works and Indonesian culture. The results of this study indicate that of the seven cultural elements in a vertical way, the work of Kwodokijo only shows six cultural elements, which are created orally are not recorded by photography. Language System. All of the works of "kwodokijo" strongly reflect the situation and conditions of the original Indonesian culture which can become the national identity, easily accessible to local and world communities from various circles.
\end{abstract}

Keywords: photography, Indonesia culture, Cultural Elements

\section{Pendahuluan}

Identitas negara Indonesia adalah memiliki, keunikan, kekhasan serta ragam kebudayaan dari Sabang hingga Merauke. Identitas ini harus diperkenalkan kepada dunia dan ditanamkan dalam jiwa masyarakat Indonesia agar kebudayaan tetap menjadi jati diri bangsa Indonesia. Kebudayaan ini meliputi kebudayaan tangible dan intangible. Kebudayaan tangible merupakan penginggalan situs bersejarah seperti candi, situs cagar budaya, artefak, monument, rumah tradisional, baju adat dan lain sebagainya yang terlihat secara fisik. Sedangkan kebudayaan intangible merupakan kebudayaan yang memiliki sifat non-bendawi atau tidak Nampak secara fisik seperti tarian, karya musik, lagu, pantun, Bahasa daerah. 
Kebudayaan merupakan hasil dari tradisi yang diturunkan dan di jaga oleh setiap generasi. Seiring perkembangan zaman kebudayaan oleh sebagain masyarakat terutama kalangan usia muda, dianggap sesuatu yang kuno, terkesan kolot atau tidak modern. Generasi muda banyak mengadopsi budaya dari negara luar yang dianggap lebih baik, keren dan modern. Hal seperti ini yang mampu mengikis rasa cinta terhadap kebudayaan Indonesia. Namun saat ini generasi 4.0 sudah mengalami

kemudahan dalam menerima informasi untuk mengetahui kebudayaan yang ada di sabang sampai Merauke, untuk menumbuhkan rasa cinta. Peranan teknologi yang berkembang pesat mampu memberikan banyak informasi yang dibutuhkan, karena teknologi informasi pada saat ini memegang peranan penting dalam sendi - sendi kehidupan manusia abad ke-21.

Hal ini membuktikan bahwa teknologi sangat berpengaruh dalam memberikan informasi mengenai kebudayaan tanpa perlu mengunjungi wilayah tertentu sebagai cara pandang baru dalam menampilkan sebuah nilai-nilai kearifan lokal untuk dapat lebih dihargai serta dipahami bagi masyarakat di kota maupun di daerah untuk menjaga dan melestarikan kebudayaan nusantara yang penuh dengan kekayaan bernilai tinggi. Media informasi yang dapat digunakan seperti google, facebook, instagram, youtube, dan banyak lagi dapat mudah diakses dan diminati oleh kalangan muda. Media tersebut dapat dimanfaatkan secara maksimal oleh para pemberi informasi, salah satunya fotografi yang dapat menjadi mata bagi banyak semua.

Fotografi sudah diidentifikasikan sebagai industri kreatif oleh Pemerintah, di mana lingkup industri kreatif mencakup 14 subsektor, antara lain: layanan komputer dan piranti lunak (software), arsitektur, radio dan televisi, periklanan, barang seni (lukisan, patung), kerajinan, desain, mode/fesyen, musik, permainan interaktif, seni pertunjukan, penerbitan-percetakan, riset dan pengembangan, film-video serta fotografi (Saryana, I, M, dkk: 2018). Sehingga pemanfaatan fotografi dan media sosial dirasa cukup efektif untuk memperkenalkan kebudayaan Indonesia kepada dunia.

\section{Kebudayaan}

Kebudayaan menurut Edward Burnett Tylor (dalam Permana, 2015) adalah sesuatu keseluruhan yang kompleks, yang didalamnya terdapat, pengetahuan, kepercayaan, moral, kesenian, hukum, adat istiadat, dan kemampuan lain yang didapatkan oleh seseorang sebagai anggota masyarakat. Kebudayaan adalah buah budi manusia yang dijadikan pedoman, nilai dan norma dalam dimensi ruang kehidupan oleh sekelompok masyarakat. Dewantara (dalam Herlambang, 2018) berpendapat bahwa kebudayaan sebagai buah budi manusia, hasil perjuangan manusia terhadap pengaruh zaman dan alam yang merupakan bukti kejayaan hidup dan penghidupannya agar tercapainya kebahagiaan dan keselamatan yang bersifat damai dan tertib. Maka, karena hal tersebut, kebudayaan tidak dapat terlepas dari karakteristik khas yang melekat pada manusia yang berada dalam ruang lingkup kehidupan masyarakat tersebut. (Herlambang, 2018).

Dalam perspektif budaya, bergantinya ruang interaksi tersebut membawa beberapa dampak di masyarakat. Perkembangan teknologi yang sangat cepat diikuti oleh cepatnya perubahan budaya di masyarakat. Kondisi ini sangat ditunjang dengan kemudahan-kemudahan yang ditawarkan oleh berbagai aplikasi teknologi. Hal ini membuat perilaku orang- orang berubah. Arah budaya juga mengalami perubahan, menuju budaya visual, di mana segala sesuatu berbasis visual. Segala sesuatu yang diputuskan atau dilakukan, semua dipengaruhi oleh hal-hal yang terlihat atau visual. Budaya visual adalah cara hidup sehari-hari di mana pemahaman dan proses pengambilan keputusan dipengaruhi oleh hal-hal yang visual. (Putri, 2016). Seperti layaknya pengalaman kita dalam bermedia visual, kita kerap mengkonsumsi simbol-simbol untuk diri kita sendiri yang membentuk suatu identitas. Kita cenderung memilih medium foto yang direproduksi dari jaman ke jaman sebagai alat untuk menyampaikan suatu representasi makna maupun pesan. Karena setiap foto, dimungkinkan untuk membuat pesan fotografis yang menjadi bagian dari praktek penandaan. Pesan tersebut merefleksikan kode-kode, nilai- nilai,dan keyakinan atas kebudayaan secara keseluruhan. 


\section{Fotografi}

Fotografi berasal dari bahasa Yunani mempunyai arti yaitu menggambar dengan bantuan cahaya dengan beberapa sifatnya mampu merekam sesuatu atau peristiwa dengan tepat dan obyektif. Fotografi sangat tepat untuk menyajikan peristiwa yang mengandung unsur berita. (Alberd, 2014). Perkembangan fotografi saat ini begitu pesat. Kemampuan fotografi tidak hanya sebatas pada kecepatan prosesnya saja namun juga dapat memoles hasil fotonya supaya menjadi suatu hasil yang berbeda dengan foto aslinya dan memiliki estetika yang begitu menawan.

Estetika fotografi meliputi dua tataran, yaitu pada tataran ideational dan estetika pada tataran teknis. Tataran ideational mengungkap nilai estetika yang berhubungan dengan gagasan, ide atau konsep. Selanjutnya tataran teknis (technical) halnya penggalian nilai estetika melalui teknik pemotretan. Estetika secara ideational dalam konteks fotografi, ditinjau sebagaimana manusia menemukan sesuatu ide dan mengungkapkannya dalam bentuk konsep, teori ataupun dalam sebuah wacana. Ide dan konsep tersebut dapat dikembangkan dan ditindaklanjuti agar menghasilkan suatu karya yang memiliki nilai estetika. Pengungkapan ide atau konsep yang terkandung tentunya memerlukan penggalian dari sudut pandang teks dan konteks (Nindhia \&Setiawan, 2019).

Dalam fotografi ada istilah fotografer yakni orang yang melakukan eksekusi perekaman. Bagi seorang fotografer profesional, objek foto tidak hanya sekadar perekaman belaka, namun harus memberikan sentuhan estetis dari berbagai komposisi. Fotografer kini begitu kreatif, tidak hanya sebatas ahli dalam menggunakan kamera tetapi juga harus ahli dalam persiapan tema foto dan pengolahan akhir untuk memberikan kesan estetik dalam nuansa foto.

Seorang fotografer pada hakikatnya adalah orang yang mempunyai keahlian dalam merawat serta mengekspresikan kepekaan optik supaya hasil bidikan objeknya dapat berkembang menjadi pengalaman estetik kemanusiaan. Hasil bidikan kameranya merupakan sebuah seni visual yang dapat menyiratkan tatanan kehidupan atau memiliki sentuhan terhadap kebudayaan. Selain itu fotografer pun dituntut agar memahami segitiga retoris yang memiliki elemen sebagaimana disebutkan oleh Wendy Hesford dan Brenda Jo Brueggemann (dalam Illahi, 2017), yakni jika analisis fotografi melibatkan gambar dalam hal subyek/konten, audien/konteks, dan perspektif.

Fotografi digunakan sebagai media untuk mengabadikan momen penting dalam kehidupan manusia, salah satunya adalah kebudayaan. Fotografi yang layak secara teknis, memiliki pesan, artistik dan estetik dalam presentasinya adalah fotografi yang baik dan berkualitas. Diperlukan keahlian dan teknik khusus dalam ilmu fotografi dalam penyampaian pesan sebuah foto, agar pesan yang terdapat didalamnya dapat tersampaikan kepada penikmat fotonya. (Nindhia \& Setiawan, 2019).

Fotografi juga diyakini sebagai bahasa, yang merupakan salah satu bentuk komunikasi visual yaitu menghadirkan objek secara akurat. Bahkan, fotografi mengomunikasikan pesan. Bahasa fotografi tidak hanya proses menghasilkan gambar oleh fotografer dengan harapan agar mampu menjelaskan atau menjabarkan kembali pada orang lain. Namun, bahasa ini juga meliputi bentuk ekspresi ide, gagasan, pemikiran, dan emosi tergantung pada fakta yang hadir. Fotografi hadir sebagai unique distinction, yakni kemampuan untuk berbicara (spoken) dan tulisan (written) serta membuat menjadi partially (not complette), out of date (tidak bertahan lama). Pengetahuan tersebut menjadi sangat penting bagi fotografer selain permasalahan teknik optimalisasi lensa. (Iskandar A, dkk, 2014). Selain itu juga fotografi dapat dijadikan sebagai karya seni, yang disebut sebagai fotografi seni. Fotografi seni merupakan foto konsep yang dibuat oleh fotografer sebagai karya seni. Fotografer sebagai seorang seniman yang akan berekspresi dalam media fotografi. Konsep dibuat oleh fotografer sesuai dengan keinginan murni dari fotografer, dan foto digunakan sebagai suatu keindahan tanpa harus dibebani pesan komersial maupun berita. (Aziz A, dkk, 2017).

\section{Metode Penelitian}

Penelitian menggunakan metode kualitatif deskriptif, penelitian terhadap analisis hasil karya fotografi yang difokuskan pada pemahaman kebudayaan Indonesia berdasarkan unsur kebudayaan secara universal. 
Teknik pengumpulan data berdasarkan studi literatur berdasarkan hasil karya fotografi yang terdapat pada akun Instagram Kwodokijo dan literatur mendalam mengenai kebudayaan. Analsis karya pada akun Instagram Kwodokijo ini berdasarkan pada teori cultural universal yang memiliki tujuh unsur kebudayaan.

\section{Hasil dan Pembahasan}

\section{Pengenalan Akun Instagram KWODOKIJO}

Akun Istagram bernama "kwodokijo" mengisi kontennya dengan hasil karya fotografi. Pada catatan hari senin, 17 Agustus 2020, akun kwodoijo memiliki 5.488 pengikut dan 3.135 diikuti oleh akun Instagram lainnya. Postingan pertama berjudul "Over Thinking", diunggah pada tanggal 30 Juni 2019 dan unggahan terakhirnya berjudul "Pernah jadi primadona pada masanya", diunggah pada tanggal 16 Agustus 2020. Total karya yang diunggah tercatat ada 96 foto, dari total karya ada 4 karya fotografi dengan konsep berbeda. 3 Karya berjudul 'Happy Monday", "Little House Reborn", dan "Don't be Sad", disebutkan merupakan konsep dari akun Instagram bernama @sebastiankisworo. Sedangkan satu foto yang memiliki konsep berbeda berjudul "Keep Smile" dengan keterangan bahwa hasil foto merupakan berasal dari Event akun instargam @fitra_pranadjaja dengan model @inventcapillano dan MUA yang digunakan@nury_yantie_mua, sekilas hasil karya foto ini berlainan dengan konsep lainnya.

Dari total karya 96, dapat disimpulkan bahwa ada 92 karya akun kwodokijo memiliki konsep dan hasil karya fotografi yang sama, yaitu gambaran dari kebudayaan Indonesia, yang terdiri kebudayaan bendawi dan non-bendawi, seperti tarian, alat music, kegiatan sehari-hari, alat memasak, car berburu, dan interaksi sosial yang dilakukan oleh masyarakat Indonesia yang membentuk kebudayaan secara utuh dan memiliki nilai sosial serta nilai estetika.

\section{Fungsi, Karakteristik dan Unsur Kebudayaan}

Fungsi dari kebudayaan yaitu mengatur manusia untuk memahami cara bertindak, berprilaku, dan bersikap dalam menjalin suatu hubungan antara mnausia dan kelompok manusia lainnya. Fungsi lainnya yaitu sebagai pedoman manusia dalam menjalani kehidupan secara social dan menjadi pembeda yang jelas anatar manusia dan binatang. Kebudayaan menjadi garis pokok mengenai garis utama mengenai perilaku yang menetapkan banyak peraturan mengenai hal yang dapat dilakukan, harus dilakukan dan tidak dapat dilakukan sebagai manusia.

Alfan (dalam Herlambang, 2018) berpendapat bahwa karakteristik kebudayaan meliputi : 1) dapat dipelajari dan dimiliki bersama oleh masyarakat; 2) diwariskan kepada generasi penerusnya;

3) diajarkan kepada siswa melalui lembaga pendidikan; 4) berbasis simbol tertentu; 5) bersifat adaptif. Dari karakteristik tersebut sudah jelas bahwa kebudayaan merupakan sesuatu hal yang perlu dipertahankan dalam kehidupan. Kebudayaan juga harus memenuhi segala hal yang dibutuhkan masyarakat. Oleh karena itu, penting sekali untuk memahami dan mempertahankan kebudayaan di tempat kebudayaan itu berasal.

Unsur kebudayaan adalah bagian yang tidak bisa dipisahkan dari sebuah kebudayaan manusia, maka dengan demikian unsur kebudayaan adalah hal yang bersifat universal atau dimiliki oleh setiap kebudayaan di seuruh penjuru dunia. Kluckhon (dalam Herlambang, 2018) membagi sistem kebudayaan menjadi tujuh unsur kebudayaan universal atau disebut kultural universal. Berikut adalah ketujuh unsur kebudayaan tersebut.

a. Sistem Bahasa;

b. Sistem Pengetahuan;

c. Sistem Kekerabatan dan Organisasi Sosial;

d. Sistem Peralatan Hidup dan Teknologi;

e. Sistem Mata Pencarian Hidup;

f. Sistem Religi dan;

g. Kesenian.

Perubahan zaman yang banyak mempengaruhi gaya hidup, menjadikan cara pandang dan mempelajari kebudayan dengan cara berbeda, menurut Agustianingrum (2020) menyatakan bahwa 
media konvensional dalam pembelajaran era revolusi industry 4.0. perlahan-lahan mulai bergeser dan kurang diminati oleh siswa generasi alpha. Dari hal tersebut dapat diartikan bahwa penyampaian sebuah makna kebudayaan di zaam sekarang haruslah dengan gaya dan cara yang lebih mengikuti zaman, salah satunya pengenalan artefak kebudayaan dengan fotografi pada akun Instagram yang ditunjukan dengan karya fotografi pada akun instragram milik KWODOKIJO.

\section{Fotografi Karya Akun Instagram KWODOKIJO}

Pada pembahasan foto milik karya akun Instagram Kwodokijo, penulis membagi foto kebudayaan ke dalam unsusr-unsur yang telah dijelaskan pada pembahasan pertama, sehingga dapat diketahui secara jelas unsur kebudayaan yang paling menonjol dari foto tersebut.

\section{a. Foto 1}

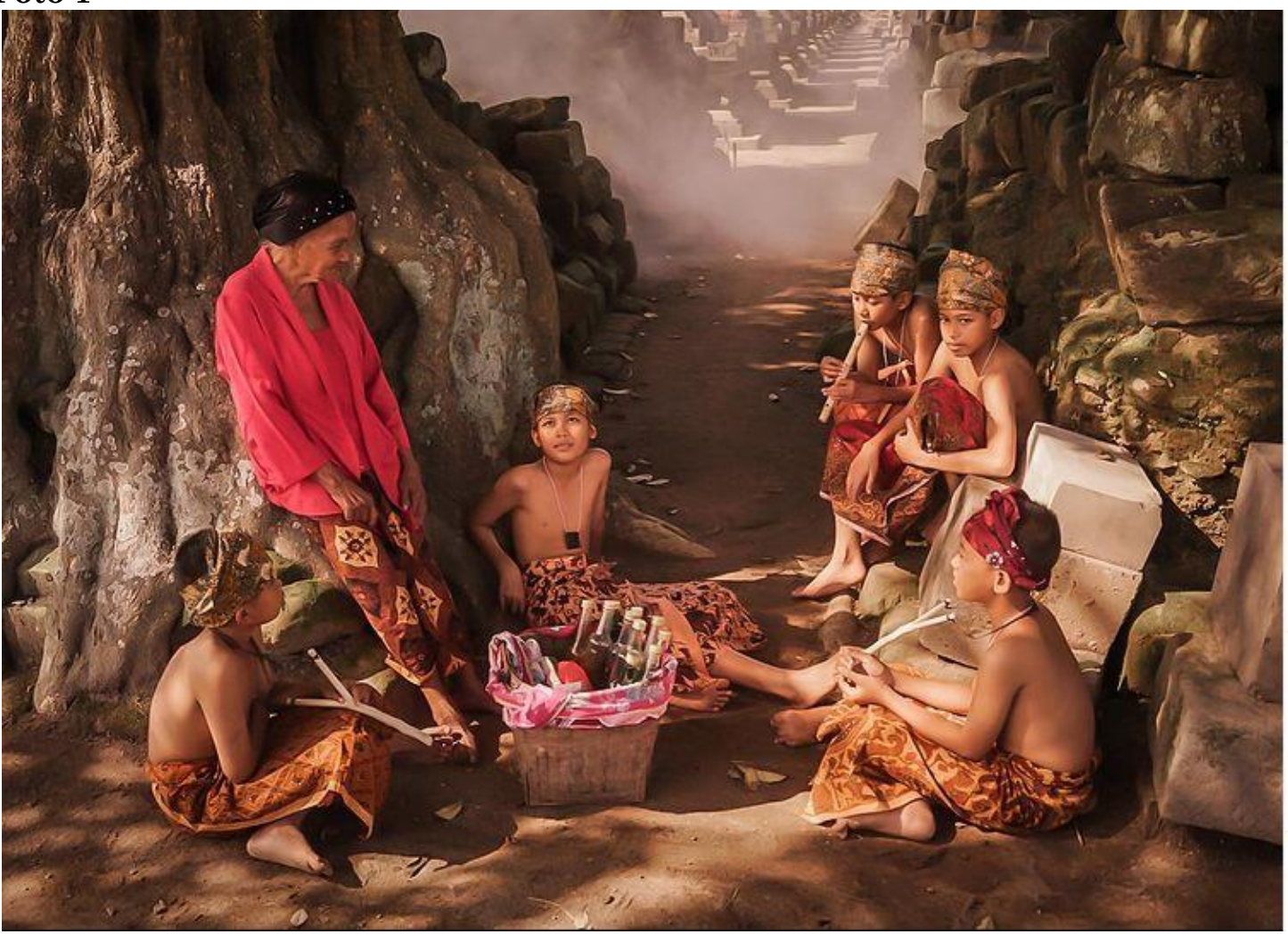

Gambar 1. Rajinlah minum jamu untuk meningkatkan imun kamuy

Sumber : https://www.instagram.com/boedi_kwodokijo/ 2020

Tabel 1. Analisis Unsur Kebudayaan Foto 1

\begin{tabular}{|l|l|l|}
\hline No. & Unsur Kebudayaan & \multicolumn{1}{c|}{ Analsisi Unsur Kebudayaan } \\
\hline 1 & Sistem Bahasa & $\begin{array}{l}\text { - Sistem Bahasa Digambarkan dengan adanya interaksi antara } \\
\text { seorang nenek menjual jamu kepada anak-anak } \\
\text { - Bahasa dilihat dari gerakan tubuh yang muncul sebagai } \\
\text { komunikasi }\end{array}$ \\
\hline 2 & Sistem Pengetahuan & $\begin{array}{l}\text { - Pada foto terlihat nenek sebagai orang tua berdiri dan anak- } \\
\text { anak dengan posisi duduk } \\
\text { - Sistem pengetahuan yang terjadi salah satunya dengan cara } \\
\text { pemberian petuah dari orang yang lebih tua kepada anak-anak } \\
\text { - Sistem pengetahuan ini dilihat secara implisit }\end{array}$ \\
\hline 3 & $\begin{array}{l}\text { Sistem Kekerabatan } \\
\text { dan Organisasi Sosial }\end{array}$ & $\begin{array}{l}\text { Terlihat interaksi antara dua generasi berbeda yang, hal } \\
\text { tersebut menunjukan sistem kekerabatan secara sosial yang } \\
\text { terjalin dengan baik. }\end{array}$ \\
\hline 4 & $\begin{array}{l}\text { Sistem Peralatan } \\
\text { Hidup dan Teknologi }\end{array}$ & $\begin{array}{l}\text { Teknologi sederhana yang dimunculkan pada foto ini adalah } \\
\text { ketapel yang di pegang oleh anak laki-laki. Ketapel ini benda } \\
\text { yang digunakan untuk bermain, yang terbuat dari kayu } \\
\text { berbentuk Y kemudian ditambahkan karet sebagai alat }\end{array}$ \\
\hline
\end{tabular}




\begin{tabular}{|c|c|c|}
\hline & & $\begin{array}{l}\text { pelengkapnya. } \\
\text { - Bakul jamu digunakan untuk membawa botol kaca berisi } \\
\text { ramuan tradisional, sebagai teknologi sederhana untuk } \\
\text { membawa benda yang digendong. }\end{array}$ \\
\hline 5 & $\begin{array}{l}\text { Sistem Mata } \\
\text { Pencarian Hidup }\end{array}$ & $\begin{array}{l}\text { - Sistem ini ditunjukan pada bakul jamu yang ditaruh dibawah, } \\
\text { lengkap dengan kain jarik untuk menggendong bakul jamu } \\
\text { - Alat tersebut digunakan sebagai salah satu alat bantu dalam } \\
\text { membawa botol kaca berisi ramuan tradisional yang di jajajkan } \\
\text { kepada masyarakat }\end{array}$ \\
\hline 6 & Sistem Religi & - - \\
\hline 7 & Kesenian & $\begin{array}{l}\text { - Pada foto terlihat salah satu anak sedang memainkan seruling } \\
\text { bamboo, sambill berbincang, bercanda tawa ia asik memainkan } \\
\text { alat music tradisional } \\
\text { - Kain jarik yang digunakan oleh orang tua dan anak-anak } \\
\text { menjadi penutup badan bagian bawah dan juga menjadi iket } \\
\text { kepala, merupakan bentuk hasil kesenian, yaitu batik } \\
\text { - Baju kebaya yang digunakan oleh nenek pada foto merupakan } \\
\text { hasil kesenian busana yang menjadi ciri khas pakaian budaya } \\
\text { jawa. }\end{array}$ \\
\hline
\end{tabular}

\section{b. Foto 2}

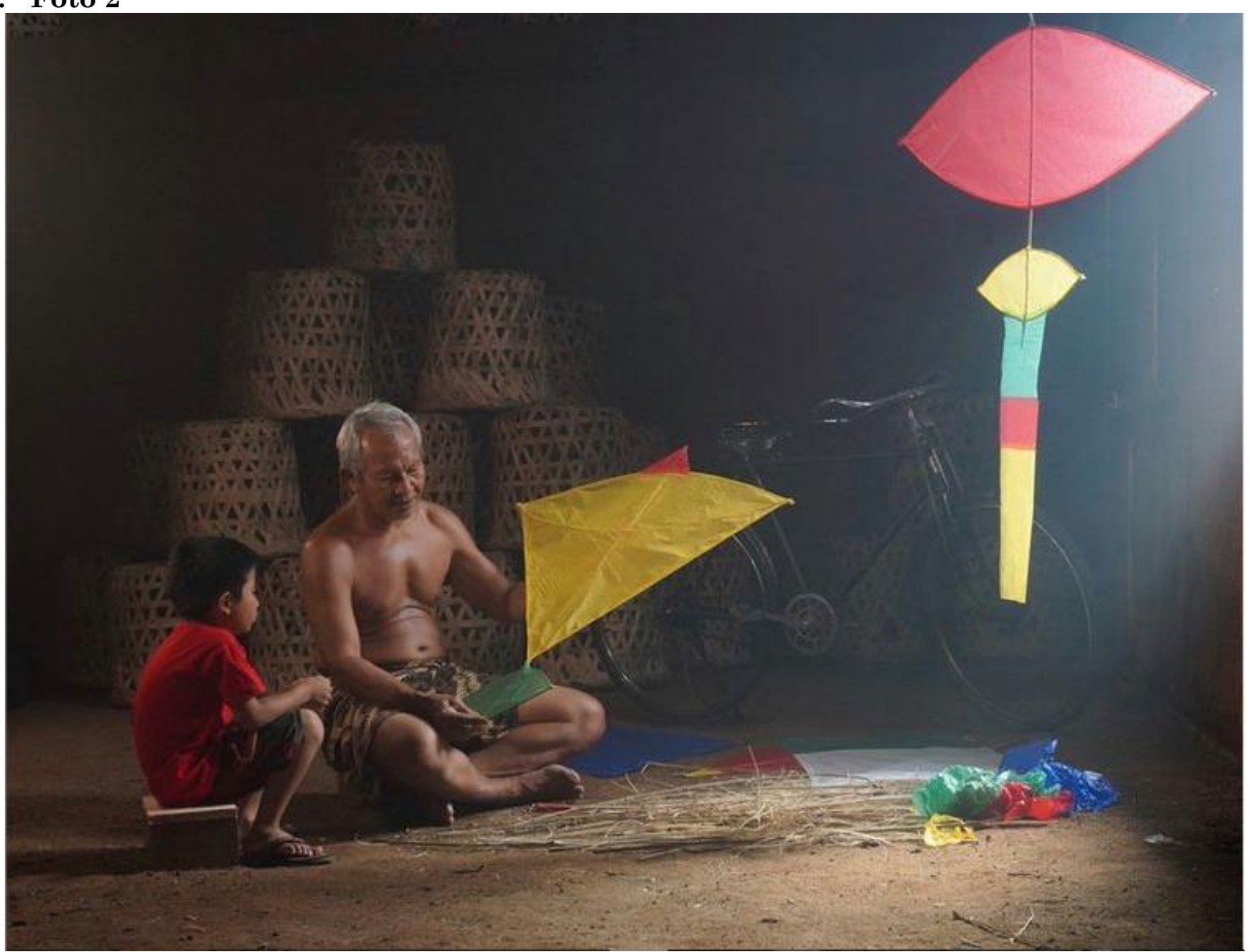

Gambar 2. Kisah cintamu jangan sampai seperti layangan putus yang terombang ambing kesana kemari terbawa angin

Sumber : https://www.instagram.com/boedi_kwodokijo/ 2020

Tabel 2. Analisis Unsur Kebudayaan Foto 2

\begin{tabular}{|l|l|l|}
\hline No. & Unsur Kebudayaan & \multicolumn{1}{c|}{ Analsisi Unsur Kebudayaan } \\
\hline 1 & Sistem Bahasa & $\begin{array}{l}\text { - Pada foto kedua terlihat ada interaksi antara seorang anak } \\
\text { dengan laki-laki tua yang sedang membuat layangan } \\
\text { - Sistem Bahasa diperlihatkan dengan Gerakan tubuh dimana } \\
\text { seolah-olah ada komunikasi antara kedua orang yang sedang } \\
\text { membahas mengenai layang-layang }\end{array}$ \\
\hline
\end{tabular}




\begin{tabular}{|c|c|c|}
\hline 2 & Sistem Pengetahuan & $\begin{array}{l}\text { - Sistem ini diperlihatkan dengan cara seorang kakek yang } \\
\text { memberitahukan mengenai sebuah layangan. Hal tersebut } \\
\text { ditunjukan dengan cara layang-layang yang sedang } \\
\text { diperlihatkan kepada anak tersebut. } \\
\text { - Pada foto terlihat sisa pengerjaan pembuatan layangan, secara } \\
\text { implisit memberikan informasi bahwa ada proses dan cara } \\
\text { membuat layang-layang sebagai sistem pegetahuan }\end{array}$ \\
\hline 3 & $\begin{array}{l}\text { Sistem Kekerabatan } \\
\text { dan Organisasi Sosial }\end{array}$ & $\begin{array}{l}\text { - Pada foto adanya interaksi dari dua generasi berbeda yang } \\
\text { menunjukan berjalannya sistem kekerabatan dan organisasi } \\
\text { sosial }\end{array}$ \\
\hline 4 & $\begin{array}{l}\text { Sistem } \\
\text { Hidup dan Teknolatan }\end{array}$ & $\begin{array}{l}\text { - Teknologi yang diabadikan pada foto yaitu sepeda ontel yang } \\
\text { dijadikan latar. Sepeda menjadi transportasi yang digunakan } \\
\text { oleh orang tua dalam berpergian. } \\
\text { - Sistem peralatan hidup pada foto ini yaitu keranjang yang } \\
\text { tersusun di bagian belakang kedua objek manusia. Keranjang } \\
\text { tersebut biasanya digunakan sebagai wadah atau tempat } \\
\text { menyimpan benda-benda yang akan dikirim kesuatu wilayah } \\
\text { tertentu }\end{array}$ \\
\hline 5 & $\begin{array}{l}\text { Sistem Mata } \\
\text { Pencarian Hidup }\end{array}$ & $\begin{array}{l}\text { - Sistem mata pencaharian hidup ini dapat digambarkan pada } \\
\text { layangan yang dibuat oleh kakek tersebut, bahwa hasil karya } \\
\text { seninya dapat menghasilkan rupiah. } \\
\text { - Keranjang bagian belakang yang menjadi latar menggambarkan } \\
\text { adanya suatu kegiatan rutin menciptakan sebuah karya seni } \\
\text { anyam yang dibentuk menjadi keranjang. Dapat menyiratkan } \\
\text { dua arti, yang pertama adalah keranjang tersebut sengaja } \\
\text { dibuat untuk menyediakan peralatan kepada banyak orang } \\
\text { atau memang membuat keranjang yang digunakan secara } \\
\text { pribadi untuk mengangkut barang tertentu. Kedua hal tersebut } \\
\text { dapat mencerimnkan adanya sistem mata pencaharian hidup. }\end{array}$ \\
\hline 6 & Sistem Religi & - - \\
\hline 7 & Kesenian & $\begin{array}{l}\text { - Layang-layang menjadi bentuk kesenian yang menjadi objek } \\
\text { utama dalam foto ini } \\
\text { - Karanjang yang dijadikan latar merupakan salah satu bentuk } \\
\text { hasil kesenian yaitu kriya anyam } \\
\text { - Kain jarik yang digunakan oleh kakek dalam foto merupakan } \\
\text { hasil kesenian, yaitu kriya batik }\end{array}$ \\
\hline
\end{tabular}

c. Foto 3

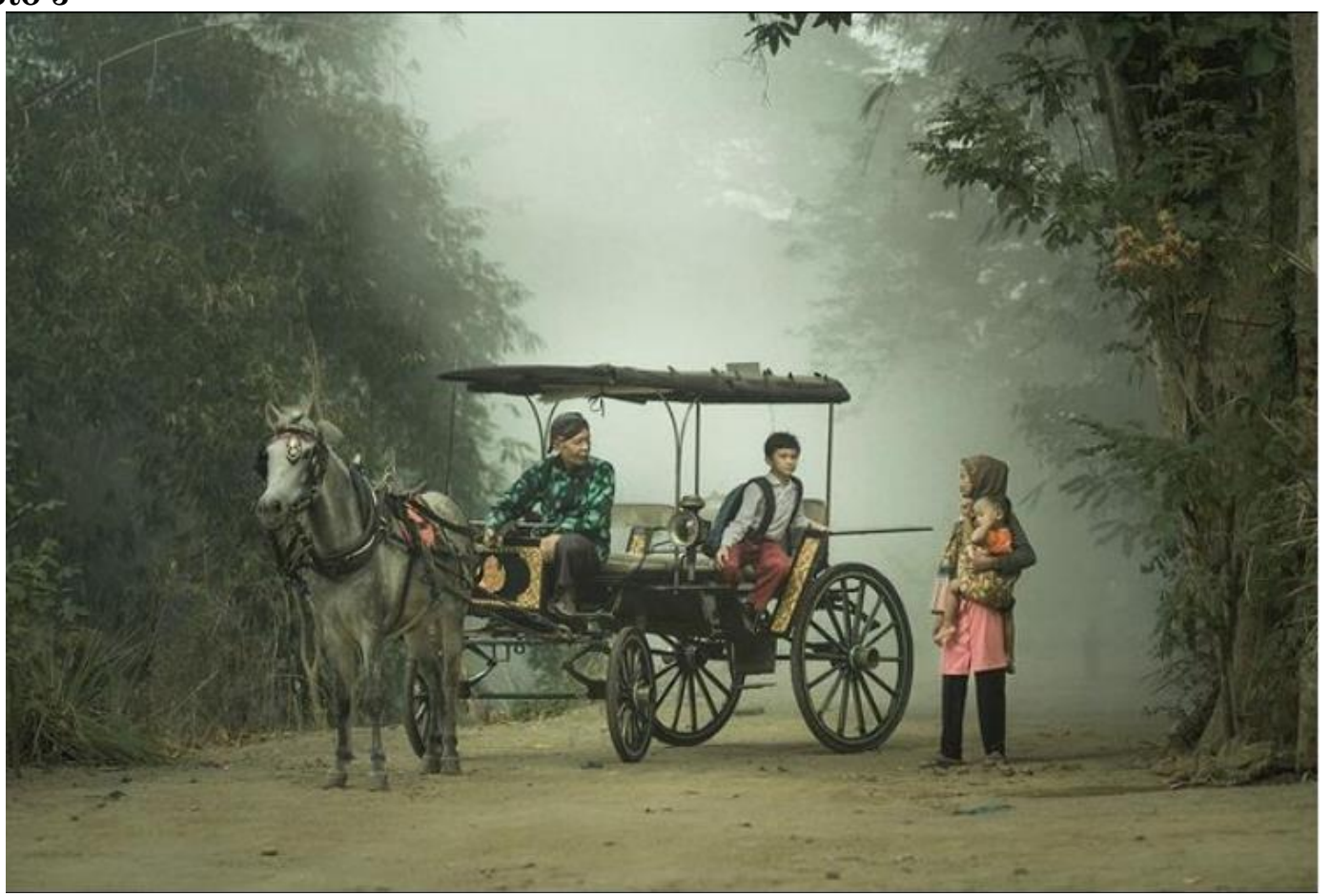

Gambar 3. Keluarga yang bisa menikmati bahagia walau dengan cara yang sederhana Sumber : https://www.instagram.com/boedi_kwodokijo/ 2020 
Tabel 3. Analisis Unsur Kebudayaan Foto 3

\begin{tabular}{|c|c|c|}
\hline No. & Unsur Kebudayaan & Analsisi Unsur Kebudayaan \\
\hline 1 & Sistem Bahasa & $\begin{array}{l}\text { - Foto ini memperlihatkan adanya Bahasa tubuh yang } \\
\text { mengisyaratkan bahwa ketiga orang yang berada di foto yaitu } \\
\text { ibu, bapak dan anak yang sedang berkomunikasi } \\
\text { - Gesture tubuh yang saling berpandangan menunjukan bahwa } \\
\text { mereka sedang berinteraksi }\end{array}$ \\
\hline 2 & Sistem Pengetahuan & $\begin{array}{l}\text { - Pada foto tergambarkan seorang anak mengenakan baju } \\
\text { sekolah dan menggendong tas, memberikan isyarat mengenai } \\
\text { adanya sistem pengetahuan pada foto tersebut. }\end{array}$ \\
\hline 3 & $\begin{array}{l}\text { Sistem Kekerabatan } \\
\text { dan Organisasi Sosial }\end{array}$ & $\begin{array}{l}\text { - Sistem oragnisasi sosial tergambar dari interaksi antara anak } \\
\text { dan orang tua yang berada di foto. Antara pengemudi delman } \\
\text { dan penumpangnya memiliki kekerabatan, bahkan } \\
\text { kemungkinanan mereka tidak memiliki ikatan persaudaraan. } \\
\text { - Sistem ini terjalin sebagai bentuk organisasi sosial yang saling } \\
\text { menghargai antara anak dan orang tua, selain itu antara } \\
\text { pedagang dan pembeli dalam bentuk jasa }\end{array}$ \\
\hline 4 & $\begin{array}{l}\text { Sistem Peralatan } \\
\text { Hidup dan Teknologi }\end{array}$ & $\begin{array}{l}\text { - Kereta kuda merupakan salah satu teknologi yang muncul } \\
\text { digunakan sebagai trasnportasi, baik manusia ataupun } \\
\text { mengangkut barang yang dibawa dari satu tempat ke tempat } \\
\text { lain. Keberadaan kereta kuda sejak zaman penjajahan, masih } \\
\text { banyak digunakan pada era } 4.0 \text { pada wilayah tertentu di } \\
\text { Indonesia. } \\
\text { - Pemilihan teknologi kereta kuda ini bukan karena termasuk } \\
\text { wilayah tertinggal, namun dianggap mudah, murah dan lebih } \\
\text { nyaman dengan teknologi kereta kuda. Sehingga diabadikan } \\
\text { sebagai teknologi yang tidak lekang oleh zaman }\end{array}$ \\
\hline 5 & $\begin{array}{l}\text { Sistem Mata } \\
\text { Pencarian Hidup }\end{array}$ & $\begin{array}{l}\text { - Kereta kuda menjadi salah satu gambaran dari sistem mata } \\
\text { pencaharian hidup, karena kereta kuda banyak digunakan } \\
\text { untuk memberikan pelayanan yang menghasilkan nominal. }\end{array}$ \\
\hline 6 & Sistem Religi & $\begin{array}{l}\text { - Salah satu objek gambar adalah seorang ibu yang } \\
\text { mneggendong anak dan mengenakan kerudung. } \\
\text { - Sistem religi sangat terlihat pada penggunaan kerudung ibu } \\
\text { tersebut, menunjukan agama islam yang diyakininya }\end{array}$ \\
\hline 7 & Kesenian & $\begin{array}{l}\text { - Hasil karya seni pada foto tergambarkan dari pakaian yang } \\
\text { dikenankan oleh bapak kusir } \\
\text { - Ada kain dengan motif batik pada pakaian kemejanya dan motif } \\
\text { batik pada blangkon yang dikenakannya } \\
\text { - Topi atau blangkon pada Bahasa jawa merupakan salah satu } \\
\text { hasil kesenian yang ikut diabadikan pada gambar }\end{array}$ \\
\hline
\end{tabular}

\section{Simpulan}

Penelitian ini menunjukan bahwa hasil karya Kwodokijo pada akun Instagram dapat memperkenalkan kebudayaan Indonesia. Ketujuh unsur kebudayaan secara universal, hasil karya fotografi kwodokijo mampu menunjukan enak unsur kebudayaan, diantaranya system pengetahuan, system kekerabatan dan organisasi social, system peralatan hidup dan teknologi, system mata pencaharian hidup, system religi, dan system kesenian. Sistem Bahasa tidak muncul baik secara lisan maupun tulisan dalam karya fotografi kwodokijo. Setiap karya yang dimunculkan mampu menunjukan identitas bangsa Indonesia, mencerminkan situasi dan kondisi kkebudayaan Indonesia. Penggunaan akun Instagram dalam memperkenalkan kebudayaan Indonesia sangat memudahkan untuk diapresiasi oleh berbagai kalangan usia dan dijangkau dunia.

\section{Daftar Pustaka}

1. Agustianingrum, N. K, dan Padmasari, A.C., 2020, Implementasi Alogaritma Decision Tree Boardgame "Dwipantara" sebagai Media Pembelajaran Sejaraj Kerajaan untuk 
Meningkatkan Minat Belajar SIswa SD, Jurnal Pendidikan Multimedia : Edsence. Vol. 2. (1). 57-84.

2. Alberd, Ahmad, 2014, Citra Positif dalam Fotografi. Jurnal Desain. Vol. 01, (3), 173-180.

3. Aziz A, John Felix, dan Candy Reggi Sonia, 2017, Eksplorasi Visual Situ Cangkuang Dalam Fotografi Seni, Jurnal CAPTURE. Vol. 9, (1).

4. Herlambang, Y.T.,2018, Pedagogik: Telaah Kritis Ilmu Pendidikan Dalam Multiperspektif, Jakarta : Bumi Aksara.

5. Hutabarat, A.G.I, dan Padmasari, A.C.,2020, Rancang Bangun Game Tradisional "Tambah Satu" Berbasisi Platform Android, Jurnal Pendidikan Multimedia : Edsence. Vol. 2, (1), 29 44.

6. Illahi, Rizki K., 2017, Penggunaan Visual Retorika Oleh Fotografer Dalam Proses Penyampaian Pesan Melalui Foto Human Interest, Jurnal JOM FISIP. Vol. 4, (2), 1-17.

7. Iskandar A, dkk, 2014, Kajian Budaya Fotografi Potrait dalam Wacana Personalitas, Jurnal Panggung. Vol. 24, (3), 308-315.

8. Kusrini., 2015, Potret Diri Digital dalam Seni dan Budaya Visual. Journal of Urban Society's Art. Vol. 2, (2) 110-122.

9. Nindhia, C.I.P dan I Nyoman Anom F.S, 2019, Estetika Ideational Foto Prewedding Style Bali. Jurnal Bahasa Rupa. Vol. 3, (1), 42-47.

10. Permana, Rahadian R, 2015, Perancangan Fotografi Desain Pelestarian Kebudayaan Tari Populer di Jawa dalam Media Coffee Table Book. Jurnal UNS.

11. Putri, Evania, 2016, Foto Diri, Representasi Identitas dan Masyarakat Tontonan di Media Sosial Instagram. Jurnal Pemikiran Sosiologi. Vol. 3, (1), 80-97.

12. Saryana I.M, Anis Raharjo, dan Amoga L.O, 2018, Desain Ilustrasi Foto Pada Baju Kaos Dengan Media Fotografi Digital Pendukung Pariwisata Budaya di Pura Tanah Lot dan Taman Ayun. MUDRA Jurnal Seni Budaya. Vol. 33, (1), 154-160.

13. L, Siany, B, Catur, A, 2009, Khazanah Antropologi Jilid 1 Kelas XI SMA dan MA, PT. Wangsa Jatra Lestari, Departemen Pendidikan Nasional. 
